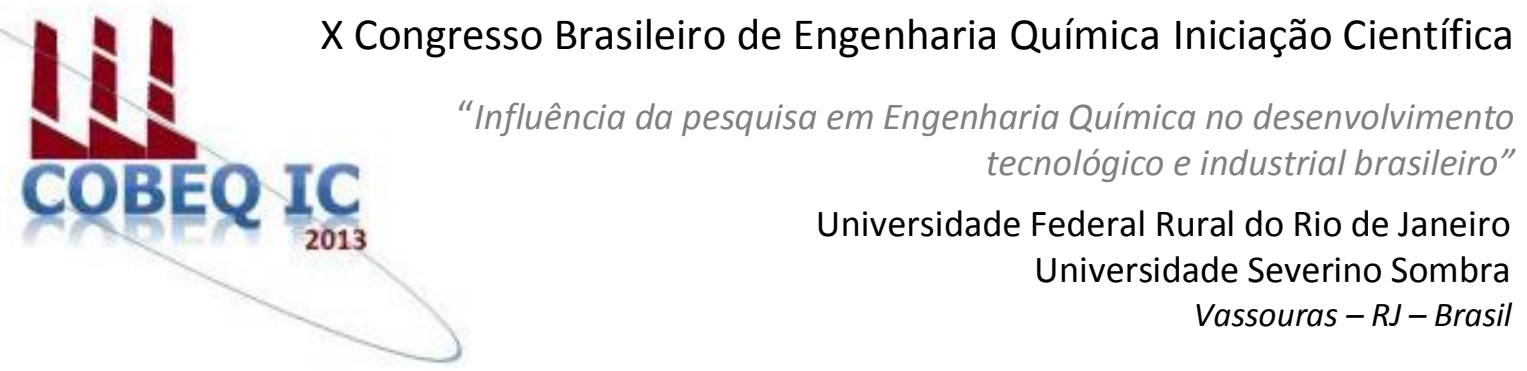

\title{
COMPARAÇÃO DE AQUECEDORES SOLARES CONFECCIONADOS COM MATERIAL RECICLÁVEL
}

\section{TEIXEIRA1, L. T.; RAMOS', S. S.; SIQUEIRA, L. B.; ROCHA², S. M. S.}

\author{
${ }^{1}$ Bolsista de extensão - PROEXT - MEC ${ }^{2}$ Docente - DETEC/UFES \\ Departamento de Engenharia e Tecnologia - Centro Universitário Norte do Espírito Santo - UFES, \\ BR 101, Km 60 - São Mateus, ES, CEP. 29.932-540, \\ e-mail: sandra.m.rocha@ufes.br
}

\begin{abstract}
RESUMO - A energia solar pode ser convertida em energia elétrica acumulada, assim como para aquecimento direto de água. Os aquecedores solares vieram como uma descoberta promissora, porém, o alto custo de instalação não permitiu que esta tecnologia chegasse à maioria da população (baixa renda). Esse tipo de aquecedor solar foi estudado, porém, os materiais utilizados na construção dos aquecedores convencionais foram substituídos por materiais recicláveis e de menor custo, construindo, assim aquecedores de baixo custo (ASBC). Este trabalho utilizou cano de PVC, tinta preto fosco, garras de polietileno (PET) acrílico, embalagens cartonadas e latas de alumínio para a construção de placas planas para o aquecimento de água para banho humano. Foram construídos dois protótipos, diferenciando apenas o material invólucro ao cano de PVC, sendo que um é com embalagem cartonada sobreposta por garrafa PET e a outra, latas de alumínio pintado de preto fosco. Efetuaram-se comparações dos dados de cada painel com a temperatura confortável para o banho humano e se concluiu que a temperatura da água aquecida pelos painéis era satisfatória e o painel de garrafa PET com embalagens cartonadas foi o de maior conveniência para instalação.
\end{abstract}

Palavras chave: Cartonadas, alumínio, PET.

\section{INTRODUÇÃO}

O Brasil possui a matriz energética mais renovável do mundo industrializado com cerca de $45 \%$ de sua produção proveniente de recursos hídricos, biomassa e etanol além da pequena contribuição por solar e eólica. Porém quando se trata da eletricidade, mais $75 \%$ da energia elétrica é proveniente de usinas hidrelétricas. Apesar de ser considerada energia limpa, a geração de energia hidrelétrica apresenta algumas desvantagens, tais como a destruição de biomas locais devido ao alagamento das áreas, destruição de culturas e histórias das cidades que são deslocadas da sua origem. Outro problema é baixa produtividade nos períodos de seca que devido às alterações climáticas mundiais têm sido cada vez maiores, comprometendo o abastecimento de cidades e indústrias.

De forma a se diminuir a dependência brasileira das hidrelétricas, cada vez mais 
fontes de energias renováveis vêm sendo estudadas. Dentre as energias renováveis, a energia solar é a que merece maior destaque no Brasil, visto que o índice de radiação solar é um dos mais altos do mundo com uma variação de 8 a $22 \mathrm{MJ} / \mathrm{m}^{2}$ ao dia.

Apesar de quase todas as regiões do Brasil segundo Rodrigues (2005), receberem mais de 2.200 horas de insolação, com um potencial equivalente a 15 trilhões de $\mathrm{MWh}$, ou seja 50 mil vezes o consumo nacional de eletricidade. Mesmo com este grande potencial de aproveitamento de energia solar, o Brasil em 2011 alcançou uma capacidade instalada total de geração elétrica de $117,135 \mathrm{MW}$ na soma das centrais de serviço público e autoprodutoras EPE(2013).

A energia solar pode ser convertida tanto em energia fotovoltaica (elétrica), quanto para aquecimento de fluidos. Neste trabalho será abordada apenas a o uso da energia solar para aquecimento.

A baixa difusão dos aquecedores solares é devido ao preço elevado dos sistemas de aquecimento, porque no Brasil a população utiliza o chuveiro elétrico como principal tecnologia para o aquecimento de água para banho, visto que o custo inicial do chuveiro elétrico é bem menor que dos aquecedores solares, porém em médio prazo a economia com a conta de energia elétrica viabiliza a instalação.

A população de baixa renda seria a mais beneficiada pelo uso de aquecedores solares, porque teriam redução no consumo energético e se enquadrariam no subsidio do governo federal, que não cobra impostos da população que consome menos de $100 \mathrm{Kw} / \mathrm{hora}$.

Assim, de forma a viabilizar a instalação de aquecedores solares em residências de baixa renda, bem como fornecer subsídios para a popularização desta tecnologia foram desenvolvidos aquecedores solar de baixo custo (ASBC), com diferentes materiais recicláveis. Para cada modelo montado foi realizado comparação dos dados obtidos, visando determinar se o sistema ASBC forneceria água à temperatura ideal para $\mathrm{o}$ banho humano.

Segundo Sprenger (2007), o banho é uma das horas mais relaxantes do dia, sendo que a temperatura ideal para causar uma sensação de bem estar durante o banho é de 40 ${ }^{\circ} \mathrm{C}$. Logo, um ASBC que atinja temperaturas próximas a $40^{\circ} \mathrm{C}$, pode ser considerado um bom substituto para o aquecedor solar de água convencional.

\section{EMBASAMENTO TEÓRICO}

A radiação solar é a radiação originada do sol, numa temperatura de cerca de $6000 \mathrm{~K} \mathrm{e}$ em um intervalo de comprimento de onda entre $0,3 \mu \mathrm{m}$ a $3,0 \mu \mathrm{m}$, com o pico de emissão ocorrendo em aproximadamente $0,50 \mu \mathrm{m}$. A radiação de onda longa é aquela originária em fontes que estão em temperaturas próximas à ambiente e, portanto, com comprimentos de onda superiores a $3,0 \mu \mathrm{m}$. Esta é a radiação emitida pela atmosfera e pela maioria das superfícies absorvedoras de energia existentes na Terra, um coletor solar ou o solo por exemplo. A radiação térmica é a fração intermediária do espectro, que se estende aproximadamente de 0,1 até $100 \mu \mathrm{m}$ e que inclui uma fração da região UV e todo o espectro visível e infravermelho

(IV) (SIQUEIRA, 2009).

A radiação solar global é medida em uma superfície horizontal. Mas para as aplicações da energia solar e para projeto de aquecedores necessita-se conhecer a radiação na superfície inclinada. Os Coletores solares de placas planas absorvem ambas as componentes diretas e difusas da radiação solar. De forma a facilitar os cálculos segundo Siqueira 2009, a radiação no plano inclinado de um coletor de orientação fixa pose ser calculada utilizando a radiação total na horizontal, porém para tal deve se conhecer a razão da radiação total em superfície inclinada pela radiação na superfície horizontal:

$$
\begin{aligned}
& R=\frac{I_{T}}{I}=\frac{I_{b}}{i} R_{b}+\frac{I_{d}}{i}\left(\frac{1+\cos \beta}{2}\right)+ \\
& +\rho\left(\frac{1-\cos \beta}{2}\right)
\end{aligned}
$$

Em que, IT é a radiação solar total horária em superfície inclinada $\left[\mathrm{kJ} / \mathrm{m}^{2}\right], \mathrm{Ib}$ é a radiação direta horária $\left[\mathrm{kJ} / \mathrm{m}^{2}\right]$; Rb é a razão entre a radiação direta horária na superfície inclinada pela radiação direta horária no plano 
horizontal [adimensional], $\mathrm{r}$ é a refletividade do solo [adimensional], $(1+\cos b) / 2$ é o fator de forma do coletor de inclinaçãob com o céu e (1-cosb) / 2 é o fator de forma do coletor.

Segundo Abogderah (1991), o coletor solar é uma forma de trocador de calor que transforma a energia solar em calor, tendo sua principal diferença em relação aos trocadores de calor convencionais que ao invés da troca de calor ocorrer entre dois fluidos com alta taxa de transferência de calor desprezando a radiação. $O$ coletor converte a energia da forma radiante, a energia solar, em calor para o fluido.

Os aquecedores utilizados no Brasil são basicamente compostos pela placa coletora e pelo reservatório térmico (boiler), adicionados das tubulações. Mas de forma a se popularizar este sistema vêm sendo estudados os aquecedores solares de baixo custo com funcionamento por termo sifão neste caso não existe o boiler, ou seja, um mesmo reservatório armazena a água fria e a água. De forma a facilitar o balanço de energia do reservatório, este será dividido em 3 regiões a de fundo, onde estará a água fria que alimentará o coletor, a de topo que receberá a água quente vinda do coletor, e uma região intermediária entre estas duas. Sendo que de acordo com Souza (2002). A placa coletora é o principal componente dos sistemas de aquecimento solar, visto que ela é responsável pela absorção e transferência da radiação solar para o fluido na forma de energia térmica.

No balanço de energia de um coletor solar plano a principal entrada de energia é a radiação solar. Ao incidir sobre a placa coletora parte desta energia será absorvida pela placa e parte será perdida por reflexão. Como este trabalho teve como objetivo determinar se as placas construídas de materiais recicláveis aqueceria a água à temperatura considerada ótima para o banho, se apresentado apenas o balanço de energia para o reservatório, de forma a verificar se o uso de um mesmo reservatório para água quente e fria não prejudicaria o sistema.

A capacidade de armazenamento de energia de um tanque com uma temperatura uniforme operando sob uma diferença de temperatura finita é dado por:

$$
Q_{S}=\left(m c_{p}\right) \Delta T_{S}
$$

Em que $\mathrm{Q}_{\mathrm{s}}$ é a capacidade de calor total para um ciclo de operação na faixa de temperatura $\Delta \mathrm{T}_{\mathrm{s}}$, com m a massa de água da unidade $(\mathrm{kg})$.

Normalmente os reservatórios dos sistemas de aquecimento solar apresentam algum grau de estratificação, em que o topo do tanque fica mais quente que o fundo, podendo sugerir assim três seções que possam apresentar uma razoável aproximação entre o projeto conservativo (tanque com única seção) e a situação limite com alto grau de estratificação. Assim, o balanço de energia será feito para cada seção do tanque. O resultado é um conjunto de três equações que podem ser resolvidas para as temperaturas das 3 seções como função do tempo. Assumindo que a massa de água que entra no reservatório vai de encontro à camada de água que apresenta uma densidade aproximadamente igual. Bem como essa quantidade de água ao entrar no tanque pode distribuir-se no caminho pelas outras seções do tanque.

Para as três seções do tanque dividido em camadas de mesma altura, com uma temperatura uniforme em cada uma delas, como apresentado na Figura 1, o fluxo de água para o coletor sempre sai do fundo, seção 3 com temperatura $T 3$, e o fluxo para o consumo sempre sai do topo, seção 1 com temperatura T1. O fluxo que sai do coletor, à temperatura $T_{s}$, retornará para a seção que está mais próxima da temperatura de saída do coletor.

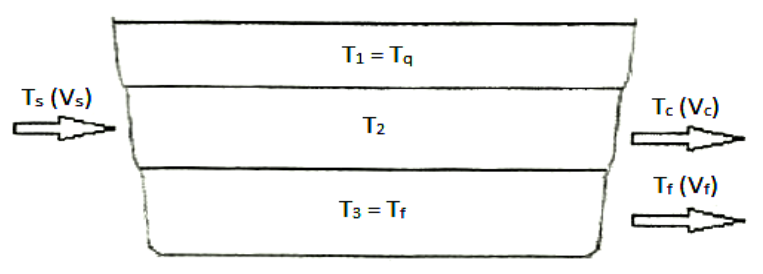

Figura $1-$ Desenho esquemático de reservatório

Considerando que a perda de calor é distribuída igualmente entre as camadas do reservatório, estas podem ser calculadas pelo coeficiente global de perdas de calor:

$$
U_{r}=\frac{Q_{\text {perdido }}}{A_{r}\left(T_{r m}-T_{a}\right)}
$$


Sendo, $A_{r}=2 A_{t}+A_{L}=2 \pi r(h+r)$

em que $r$ é o raio do cilindro e $h$ sua altura; Trm é a temperatura media do reservatório (calculada por média aritmética), $T a$ é a temperatura ambiente e Qperdido é o calor total perdido devido à transferência de calor para o meio ambiente através do topo e da lateral do reservatório.

A mistura do volume de água quente $(V q)$ à temperatura $T 1$ com o volume de água fria $(V f)$ à temperatura $T f$, determina o volume de água para consumo $(V c)$ em cada hora a uma temperatura de consumo $T q$ préestabelecida. Portanto é conhecido $T f$ e $T 1$ $(T 1=T q)$ a serem misturadas para se obter $T c$.

Ao relacionar os volumes considerados em cada seção com as temperaturas correspondentes chega-se a seguinte igualdade:

$$
T_{e} V_{c}=T_{f} V_{f}+T_{q} V_{q}
$$

Como:

$$
V_{c}=V_{f}+V_{q}
$$

Isolando $\mathrm{V}_{\mathrm{f}}$ na Equação 6 e substituindo na Equação 5, obtemos:

$$
V_{q}=\frac{V_{c}\left(T_{c}-T_{f}\right)}{T_{q}-T_{f}}
$$

A temperatura no reservatório é determinada pela troca de calor entre as três seções. Na seção 1 ouve perda de calor para a seção 2. A equação que relaciona essa perda de calor $\left(\mathrm{Q}_{1-2}\right)$ é dada por:

$$
Q_{1-2}=V_{q} C_{p}\left(T_{2}-T_{1}\right)
$$

$\mathrm{O}$ calor útil $\left(\mathrm{Q}_{\mathrm{u}}\right)$ agregado a água que sai do reservatório $\left(T_{3}=T_{f}\right)$ é obtido pela variação da temperatura vinda do coletor e vazão mássica de saída (considerando constante em uma hora), demonstrado abaixo:

$$
Q_{u}=V_{s} C_{p}\left(T_{f}-T_{e}\right)
$$

Considerando que a massa de água que sai do coletor entra na camada intermediária do reservatório, que por sua vez está a uma temperatura maior em relação a $T_{2}$, tenderá a se deslocar para a superfície, já que há diferença de densidade. Assim a quantidade de calor agregado à água superficial a cada hora é: $\mathrm{V}_{\mathrm{s}}\left(\mathrm{T}_{\mathrm{s}}-\mathrm{T}_{1}\right)$.

Abaixo segue as equações que relacionam o balanço energético de cada camada. Em que as duas primeiras parcelas da fração são relacionadas a perda de calor e a terceira ao ganho de energia.

Camada 1:

$$
\begin{aligned}
& T_{1}^{+} \\
& =T_{1} \frac{V_{q} C_{p}\left(T_{2}-T_{1}\right)-\frac{Q_{\text {Perdido }}}{3}+V_{s} C_{p}\left(T_{s}-T_{e)}\right.}{m C_{p}}
\end{aligned}
$$

Camada 2:

$T_{2}^{+}$

$=T_{2} \frac{V_{q} C_{p}\left(T_{3}-T_{2}\right)-\frac{Q_{\text {erdido }}}{3}+V_{s} C_{p}\left(T_{1}-T_{2)}\right.}{m C_{p}}$

Camada 3:

$T_{3}^{+}$
$=T_{3} \frac{V_{q} C_{p}\left(T_{f}-T_{3}\right)-\frac{Q_{\text {serdido }}}{3}+V_{s} C_{p}\left(T_{2}-T_{3}\right)}{m C_{p}}$

\section{MATERIAIS E MÉTODOS}

As placas coletoras foram construídas com garrafas PET e embalagens cartonadas e outra com latas de alumínio (Figura 2), para aquecer água suficiente para um reservatório (caixa d'água) de 150L foram utilizadas 4 placas. O mesmo reservatório foi utilizado para ambas as placas coletoras.

Para a construção das placas coletoras foi utilizado canos de PVC de $20 \mathrm{~mm}$ de diâmetro, conectadas por " $\mathrm{T}$ " para atingir o formato apresentado na Figura 2. Os canos foram pintados de preto fosco, de forma a minimizar as predas de calor por reflexão.

A placa coletora de garrafas PET e embalagens cartonadas, envolveram o cano com garrafa PET cristal de $2 \mathrm{~L}$, de forma a propiciar o "efeito estufa" no cano, dentro desta garrafa foi adicionada uma embalagem 
cartonada com o alumínio perpendicular a incidência do sol, de forma a refletir a luz para os canos que pintados de preto absorveriam esta luz.

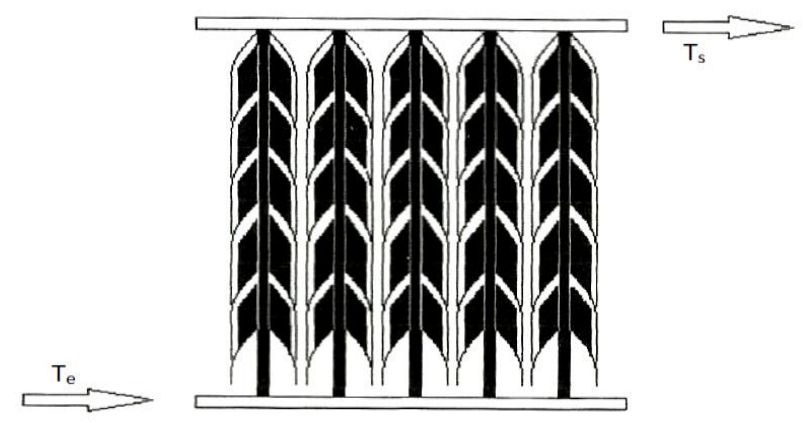

Figura 2 - Desenho esquemático da placa coletora

A placa coletora construída com latas de alumínio utilizou a mesma estrutura de canos de PVC, porém estes foram envoltos em latas de alumínio de $355 \mathrm{~mL}$ pintadas de preto fosco.

A caixa d'água teve que ser adaptada para facilitar o termo sifão (Figura 3). Esta adaptação consistiu na instalação de flange de $3 / 4$, na parte superior ( $80 \%$ da altura da caixa d'água), para abastecimento de água, dois na parte intermediária, um de frente para o outro (60\% da altura da caixa d'água), para consumo e para entrada de água quente, proveniente do painel aquecedor e o quarto na parte inferior (10\% da altura), para a saída de água fria para o painel. Também foi conectada uma boia juntamente com uma mangueira, para forçar que a água fria fosse direto para o fundo do reservatório. No final dessa mangueira um redutor de turbulência foi instalado para que não houvesse mistura da água.

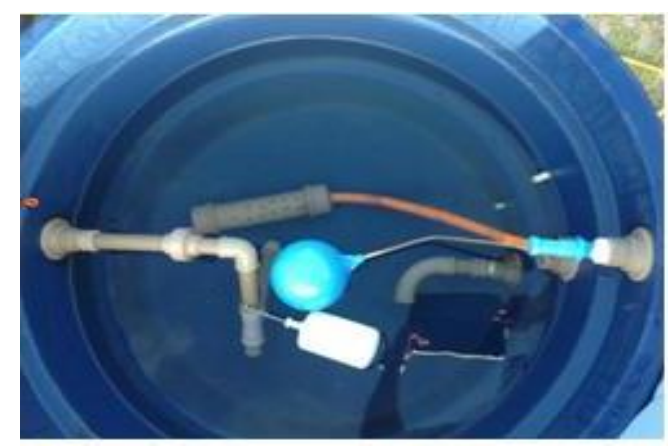

Figura 3 - Interior do reservatório.

\section{RESULTADOS E DISCUSSÕES}

Em dias de sol, com céu praticamente sem nuvens, as coletas foram realizadas em três dias para cada painel, medindo a temperatura a cada 20 minutos, a média destes resultados pode ser vista na Figura 4.

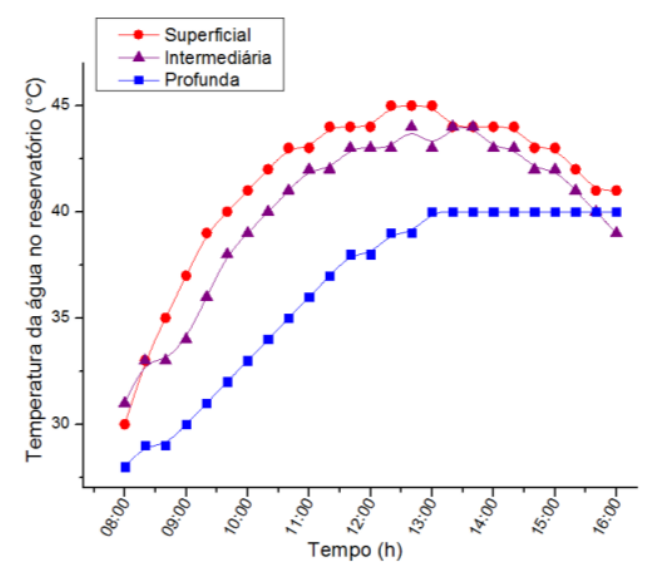

Figura 4 - Temperatura do Reservatório para a placa de PET

$\mathrm{Na}$ Figura 4 é possível observar que a temperatura da água do reservatório foi superior a $40^{\circ} \mathrm{C}$ a partir de $11 \mathrm{~h} 00 \mathrm{~min}$ nas faixas de água superficial e intermediária, e a partir de $13 \mathrm{~h}$ para a água profunda da caixa d'água. Como comentado anteriormente, a temperatura ideal para o banho humano é próxima a $40^{\circ} \mathrm{C}$ e como a temperatura no reservatório é superior a esse valor, um misturador necessita ser instalado no reservatório para que a água esteja confortável para o banho. Para a faixa de temperatura profunda, a temperatura foi aumentando gradativamente, de forma a ter um alcance maior à partir das 13

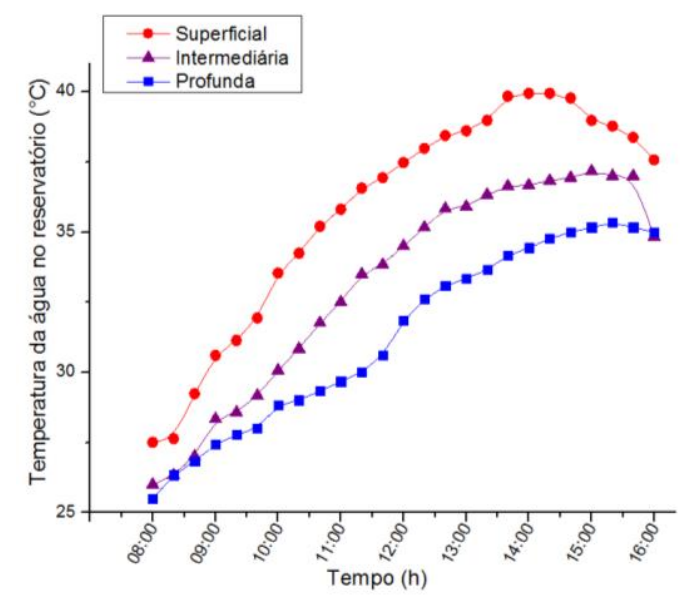

Figura 5 - Temperatura do Reservatório para a placa de Alumínio

Comparando os dados da Figura 4 e 5 pode se observar que a temperatura da água profunda do painel de garrafas PET com 
embalagens cartonadas é equiparada a temperatura superficial do painel de latas de alumínio, mostrando assim, uma maior eficiência do painel de garrafas PET. Essa diferença pode ser explicada porque $\mathrm{o}$ alumínio possui um alto calor específico, isso significa que com uma pequena adição ou remoção de calor, a temperatura varia muito. Então quando há perda de calor por convecção na superfície da lata de alumínio, ocasionada, a uma queda considerável de temperatura no interior da lata de alumínio, diminuindo, por consequência, a transferência de calor para a tubulação de PVC, este fenômeno deve ser considerado porque na região dos testes a incidência de ventos é muito grande. Por sua vez a garrafa PET apresenta baixo calor específico e não sofre grandes perdas por convecção, bem como também irá minimizar a perda de calor por radiação, devido ao efeito estufa ao redor dos canos de PVC.

A Tabela 3 mostra a perda térmica para o reservatório quando utilizado o painel de garrafa PET, por ter atingido a maior temperatura.

Tabela 3 - Média das temperaturas com a perda térmica para o reservatório.

\begin{tabular}{c|c|c|c|c|c}
\hline Horário & $\begin{array}{c}\mathbf{T}_{\mathbf{r m}} \\
\left({ }^{\circ} \mathbf{C}\right)\end{array}$ & $\begin{array}{c}\mathbf{T}_{\mathbf{a}} \\
\left({ }^{\circ} \mathbf{C}\right)\end{array}$ & $\begin{array}{c}\Delta \mathbf{T} \\
\left({ }^{\circ} \mathbf{C}\right)\end{array}$ & $\begin{array}{c}\mathbf{U}_{\mathbf{r}} \\
\left(\mathbf{k J} / \mathbf{m}^{2} \mathbf{K}\right)\end{array}$ & $\begin{array}{c}\mathbf{Q}_{\mathbf{p}} \\
(\mathbf{k J})\end{array}$ \\
\hline $08: 00$ & 29,7 & 22,9 & 6,8 & 3,558 & 35,6 \\
\hline $09: 00$ & 33,7 & 23,8 & 9,9 & 3,576 & 52,0 \\
\hline $10: 00$ & 37,7 & 24,7 & 13 & 3,594 & 68,7 \\
\hline $11: 00$ & 40,3 & 25,6 & 14,7 & 3,612 & 78,1 \\
\hline $12: 00$ & 41,7 & 26,5 & 15,2 & 3,630 & 81,1 \\
\hline $13: 00$ & 42,7 & 27,4 & 15,3 & 3,648 & 82,0 \\
\hline $14: 00$ & 42,3 & 28,3 & 14 & 3,666 & 75,4 \\
\hline $15: 00$ & 41,7 & 29,2 & 12,5 & 3,684 & 67,7 \\
\hline $16: 00$ & 40 & 28,6 & 11,4 & 3,672 & 61,5 \\
\hline
\end{tabular}

\section{CONCLUSÃO}

Com os testes realizados e com os dados analisados, o painel de latas de alumínio atingiu temperaturas relativamente boas, porém sua resistência ao translado não é tão boa e sua construção necessita de ferramentas mais sofisticadas, dificultando o acesso da população de baixa renda.

Já para o painel de garrafas PET constatou-se que possui maior resistência ao intemperismo, pois seu material é resistente a degradação do clima, além de ser melhor no translado do mesmo. As temperaturas atingidas foram favoráveis ao banho humano, sendo necessário até uma mistura para não haver desconforto para banho.

Portanto, o painel que mais se sobressaiu, dentre os testes, foi o painel de garrafa pet com caixas cartonadas, por possuir uma maior resistência ao intemperismo, aquecer a água a maiores temperaturas e ser de fácil construção, possibilitando a qualquer indivíduo a construção do mesmo.

\section{REFERÊNCIAS}

ALANO, J. A. (2004), Manual sobre a construção e instalação do aquecedor solar com descartáveis. Tubarão, Santa Catarina, Brasil.

SIQUEIRA, D. A. Estudo de desempenho do aquecedor solar de baixo custo. Dissertação (mestrado) - Universidade Federal de Uberlândia, Programa de PósGraduação em Engenharia Química. Uberlândia 2009.

SPRENGER, R. L. (2007), Aplicação do sistema fechado no aquecedor solar de água de baixo custo para reservatórios residenciais isolados termicamente: concepção e comissionamento de um sistema-piloto de testes. Curitiba, Brasil.

ABOGDERAH, M. M., ISMAIL, K. A. R. (1991), Performance of a heat pipe solar collector.

RODRIGUES, D. (2005), Um banho de sol para o Brasil, São Paulo.

SOUZA, L. G. M., GOMES, U. U. (2002), Viabilidades térmicas, econômica e de materiais da utilização de tubos de PVC como elementos absorvedores em coletores de um sistema de aquecimento de água por energia solar, tese (doutorado) UFRN.

\section{AGRADECIMENTOS}

Agradecemos a Pró-Reitoria de Extensão (ProEx) pelo financiamento das bolsas e dos materiais utilizados. A Brasil Ambiental pela parceria na realização das oficinas. 